\title{
Association between Vitamin D, Fasting Blood Glucose, HbA1c and Fasting Lipid Profile in Euglycemic Individuals
}

\author{
Vijetha Shenoy, Priyanka Datta, Krishnananda Prabhu and Kriti Singh \\ Department of Biochemistry, Kasturba Medical College, Manipal University, Manipal, Karnataka, India \\ Correspondences should addressed to: Vijetha Shenoy; vijethashy@gmail.com
}

Received date: 16 October 2013; Accepted date: 24 December 2013; Published date: 21 February 2014

Academic Editor: Naji J. Aljohani

Copyright (C) 2014. Vijetha Shenoy, Priyanka Datta, Krishnananda Prabhu and Kriti Singh. Distributed under Creative Commons CC-BY 3.0

\begin{abstract}
In addition to biological actions of vitamin $\mathrm{D}$ such as calcium absorption, regulation of bone and mineral metabolism, studies have shown that Vitamin D is necessary for normal insulin secretion. Vitamin D influences insulin production and secretion through its effect on calcium and phosphorous metabolism. Vitamin D modifies insulin response by acting on receptor gene. Vitamin D deficiency has been implicated in decreased insulin secretion and increased insulin resistance. Objective: To measure and correlate vitamin D with fasting plasma glucose, HbA1c and fasting lipid profile in euglycemic individuals. Methods: Ethics clearance was obtained prior to data collection. After an overnight fast, blood samples were collected for fasting plasma glucose, lipid profile, HbA1c and vitamin D from euglycemic individuals who consented to participate. Vitamin D assay was estimated in Elecsys 2010 by ECLIA method. Plasma glucose was estimated by Hexokinase method. Serum fasting lipid profile was estimated in Cobas 6000 (Roche), and HbA1c measured using ion exchange HPLC method using Biorad Variant II turbo. Results: There was an inverse correlation between vitamin $\mathrm{D}$ and fasting plasma glucose $(\mathrm{p}<0.001)$; Vitamin D and HbA1c $(\mathrm{p}<0.001)$ in groups 1 and 3 . There was also a significant inverse correlation of Total cholesterol $(p=0.05)$, total cholesterol / HDL ratio $(p<0.001)$ with Vitamin D and significant direct correlation of HDL with vitamin D levels in groups 1 and 3. Conclusion: Deficiency of vitamin D can predispose to dysregulation of glucose and lipoprotein metabolism. There may be a role for vitamin $\mathrm{D}$ in better management of diabetes and dyslipidemia.
\end{abstract}

Key words: Vitamin D, Type 2 Diabetes mellitus, dyslipidemia

Cite this Article as: Vijetha Shenoy, Priyanka Datta, Krishnananda Prabhu and Kriti Singh (2014), "Association between Vitamin D, Fasting Blood Glucose, HbA1c and Fasting Lipid Profile in Euglycemic Individuals," Journal of Research in Diabetes, Vol. 2014 (2014), Article ID 929743, DOI: 10.5171/2014.929743 


\section{Introduction}

The nature's own product, an ancient hormone produced in the skin by sun exposure, is Vitamin D. It is hydroxylated by liver to form 25-hydroxy vitamin D [25(OH) $\mathrm{D}]$, which is the predominant form of vitamin D in the circulation. (Ponda MP et al 2012) Vitamin $\mathrm{D}$ has many biological actions including calcium absorption, regulation of bone and mineral metabolism, muscle strengthening, cellular proliferation and differentiation, immune system modulation, inhibition of rennin synthesis and erythropoiesis etc. (De Luca HF 2004)

Animal studies have shown that Vitamin D is necessary for normal insulin secretion. Vitamin D reduces insulin resistance through regulation of the insulin receptor gene and its effects on calcium and phosphorous metabolism. (Nada AM 2013) Several studies have shown a role of vitamin $D$ in insulin production, secretion and sensitivity. (Kositsawat JMDM et al 2010, Taheri E et al. 2012, Maxwell CS and Wood RJ 2011) Also, vitamin $\mathrm{D}$ deficiency has been implicated in decreased insulin secretion and increased insulin resistance which is the hallmark of type 2 diabetes mellitus. Further, type 2 diabetes mellitus and vitamin $\mathrm{D}$ deficiency have common predisposing factors such as obesity, less physical inactivity and ageing.(Rodriguez E et al.2009) Studies have also shown vitamin D supplements in deficient individuals have resulted in improvement in insulin secretion and glucose tolerance. (Cade C and Norman AW. 1986, Bourlon PM, Billaudel B and FaureDussert A. 1999, Maestro B et al 2000, Talaei A, Mohamadi M and Adgi Z. 2013)

Cardiovascular disease (CVD) is the most common cause of death and disability in the world as well as in India. Efforts have been made to identify modifiable risk factors to prevent atherosclerosis. There is now increasing evidence through many epidemiological studies that vitamin D deficiency was closely associated with increased risk of major adverse CVD events. (Wang C 2013, Wang TJ et al 2008)
Vitamin D deficiency has been a global public health problem. The goal of this study was to measure and correlate total plasma vitamin D, fasting plasma glucose, glycated hemoglobin (HbA1c) and fasting lipid profile in euglycemic individuals.

\section{Materials and Methods}

\section{Study Subjects}

274 euglycemic individuals of 30- 75 years age, who visited hospital between March 2013 to July 2013 for general health check up, who satisfy our inclusion criteria were enrolled for this study.

\section{Study Groups}

Individuals were divided into three groups according to their plasma vitamin D levels: group $1(<20 \mathrm{ng} / \mathrm{ml})$, group $2(20-30 \mathrm{ng} / \mathrm{ml})$, and group $3(>30 \mathrm{ng} / \mathrm{ml})$

\section{Exclusion Criteria}

Patients suffering from diabetes mellitus, mal-absorption, cancer, pregnant women, patients with cardiac, hepatic, renal, diseases and those on long term medications were excluded from this study.

\section{Ethical Statement}

Ethics clearance was obtained prior to data collection from the institutional ethics committee, Kasturba Hospital, Manipal University, Manipal, India. Informed consent was obtained from every participant before their participation.

\section{Sample Collection}

Using aseptic precautions, $4 \mathrm{ml}$ of fasting venous blood was collected in a syringe. It was equally aliquoted in red, grey and lavender vacutainers. Red capped vacutainers were used for estimation of lipid profile and total plasma vitamin D, grey capped vacutainers were used for estimation of blood sugar and lavender vacutainers were used for estimation of HbA1c. 


\section{Methods}

Total vitamin D assay was estimated in Elecsys 2010 by ECLIA method. Glucose was estimated by Hexokinase method. Fasting lipid profile was estimated by kit method. All the above parameters were measured in auto analyzer Cobas 6000 (Roche Diagnostics), and $\mathrm{HbA} 1 \mathrm{c}$ was measured in BIORAD variant II turbo using ion exchange High performance liquid chromatography method.

\section{Statistical Analysis}

Data was compiled and statistical analysis was done using Statistical Package for the Social Sciences (SPSS) 16.0. Data were expressed as mean \pm standard deviation. Wherever appropriate, Independent student t test, ANOVA were used. $P$ value $<0.05$ was considered as statistically significant.

\section{Results}

Total of 146 males and 128 females participated in this study. The mean age of subjects was $49.89 \pm 16.40$ years. The general characteristics of the studied population are shown in Table 1.

Table 1: Demographic profile of the subjects

\begin{tabular}{|l|l|l|}
\hline Age Groups (Mean Age) & Males & Females \\
\hline $30-40(34.7 \pm 3.9)$ & 48 & 32 \\
\hline $41-50(45.8 \pm 2.6)$ & 25 & 29 \\
\hline $51-60(55.3 \pm 2.6)$ & 30 & 35 \\
\hline $61-75(68.8 \pm 5.2)$ & 30 & 45 \\
\hline
\end{tabular}

Groups 1 and 3 showed an inverse correlation between vitamin $\mathrm{D}$ and fasting plasma glucose $(\mathrm{p}<0.001)$, Vitamin $\mathrm{D}$ and HbA1c $(p<0.001)$. We also observed a significant inverse correlation of Total cholesterol $(\mathrm{p}=0.05)$, and total cholesterol /
HDL ratio $(\mathrm{p}<0.01)$ with vitamin $\mathrm{D}$ respectively, and significant direct correlation of HDL with vitamin D levels Except for triglycerides, other biochemical parameters also showed significant correlation between groups 1 and 2 . 
Table 2: Correlation of Vitamin D with biochemical parameters

\begin{tabular}{|c|c|c|c|}
\hline & Group $1(n=122)$ & Group $2(n=77)$ & Group $3(n=75)$ \\
\hline $\begin{array}{l}\text { Name of the } \\
\text { biochemical } \\
\text { parameter }\end{array}$ & $\begin{array}{l}\text { Mean } \pm \text { Standard } \\
\text { Deviation }\end{array}$ & $\begin{array}{l}\text { Mean } \pm \text { Standard } \\
\text { Deviation }\end{array}$ & $\begin{array}{l}\text { Mean } \pm \text { Standard } \\
\text { Deviation }\end{array}$ \\
\hline HbA1c & $5.78 \pm 0.42$ & $5.55 \pm 0.43$ & $5.39 \pm 0.39$ \\
\hline$P$ value & & $<0.001 *$ & $<0.001^{*}$ \\
\hline $\begin{array}{l}\text { Fasting Blood } \\
\text { Glucose }\end{array}$ & $98.51 \pm 11.05$ & $95.54 \pm 9.01$ & $91.72 \pm 8.64$ \\
\hline$P$ value & & $<0.001 *$ & $<0.001^{*}$ \\
\hline Total Cholesterol & $194 \pm 45.90$ & $178 \pm 36.99$ & $167 \pm 33.83$ \\
\hline P value & & $0.05^{*}$ & $0.001^{*}$ \\
\hline Triglycerides & $149 \pm 56.92$ & $134 \pm 60.95$ & $114 \pm 38.27$ \\
\hline$P$ value & & 0.253 NS & $0.001^{*}$ \\
\hline HDL- C & $38.41 \pm 11.32$ & $46.72 \pm 13.79$ & $51.22 \pm 11.61$ \\
\hline$P$ value & & $0.001 *$ & $<0.001^{*}$ \\
\hline LDL-C & $115 \pm 30.20$ & $102 \pm 29.62$ & $93 \pm 27.60$ \\
\hline$P$ value & & $0.042 *$ & $<0.001^{*}$ \\
\hline $\begin{array}{l}\text { Total } \\
\text { cholesterol/HDL } \\
\text {-C ratio }\end{array}$ & $5.25 \pm 3.25$ & $3.64 \pm 1.21$ & $2.94 \pm 1.20$ \\
\hline$P$ value & & $0.001 *$ & $<0.001^{*}$ \\
\hline Vitamin D & $9.93 \pm 4.04$ & $23.22 \pm 2.15$ & $38.79 \pm 9.05$ \\
\hline value & & $<0.001^{*}$ & $<0.001 *$ \\
\hline
\end{tabular}

NS- not significant*- significant

Vijetha Shenoy, Priyanka Datta, Krishnananda Prabhu and Kriti Singh (2014), Journal of Research in Diabetes, DOI: $10.5171 / 2013.929743$ 
Table 3: Age wise distribution of biochemical parameters

\begin{tabular}{|c|c|c|c|c|}
\hline Groups & $\begin{array}{l}\text { Group } 1 \\
\text { (30-40 Years) }\end{array}$ & $\begin{array}{l}\text { Group } 2 \\
\text { (41-50 years) }\end{array}$ & $\begin{array}{l}\text { Group } 3 \\
\text { (51-60 years) }\end{array}$ & $\begin{array}{l}\text { Group } 4 \\
\text { (61-75 years) }\end{array}$ \\
\hline & Mean \pm S.D. & Mean \pm S.D. & Mean \pm S.D. & Mean \pm S.D. \\
\hline Vitamin D & $26.14 \pm 10.2$ & $22.15 \pm 10.8$ & $20.25 \pm 9.1$ & $18.5 \pm 8.2$ \\
\hline Total cholesterol & $174.3 \pm 31.2$ & $180 \pm 25.53$ & $194.9 \pm 44.3$ & $180.2 \pm 34.6$ \\
\hline Triglycerides & $123.8 \pm 60.0$ & $120.8 \pm 49.28$ & $149.6 \pm 66.1$ & $127.8 \pm 60.8$ \\
\hline HDL- Cholesterol & $50.1 \pm 10.2$ & $48.1 \pm 12$ & $45.8 \pm 12$ & $48.6 \pm 11.2$ \\
\hline LDL- Cholesterol & $112.6 \pm 31.4$ & $120.7 \pm 40$ & $114.3 \pm 31$ & $103.8 \pm 36.58$ \\
\hline $\mathrm{HbA1c}$ & $5.5 \pm 0.4$ & $5.6 \pm 0.43$ & $5.61 \pm 0.41$ & $5.7 \pm 0.48$ \\
\hline $\begin{array}{l}\text { Fasting Blood } \\
\text { Sugar }\end{array}$ & $94.24 \pm 10.6$ & $94.7 \pm 7.5$ & $97.71 \pm 12$ & $96.52 \pm 8.68$ \\
\hline
\end{tabular}

There is no statistically significant difference in biochemical parameters according to different age groups.

Table 4: Correlation of vitamin D with lipid parameters in Males and Females

\begin{tabular}{|l|l|l|}
\hline & male & female \\
\hline Total cholesterol & $r=-0.2$ & $r=0.03$ \\
\hline Triglycerides & $r=-0.2$ & $r=-0.1$ \\
\hline HDL- Cholesterol & $r=0.2$ & $r=0.3$ \\
\hline LDL- Cholesterol & $r=-0.2$ & $r=-0.01$ \\
\hline HbA1c & $r=-0.3$ & $r=-0.3$ \\
\hline
\end{tabular}

In males and females, there was inverse correlation between vitamin $\mathrm{D}$ and $\mathrm{HbA1c}$, triglycerides and LDL, and significant direct correlation of HDL with vitamin D levels. We observed negative correlation in males between vitamin $\mathrm{D}$ and total cholesterol but not in females.

Vijetha Shenoy, Priyanka Datta, Krishnananda Prabhu and Kriti Singh (2014), Journal of Research in Diabetes, DOI: $10.5171 / 2013.929743$ 


\section{Discussion}

In this study, vitamin D3 level showed a significant negative correlation to fasting plasma glucose (FPG). This is in agreement with several studies which found the same association (Ken C C et al 2004, Ashraf AP et al 2011, Jessica A A and Ambika A 2010). Such negative correlation was also demonstrated in Middle Eastern population. (Marie-H. G et al 2009).The association between vitamin D3 and HbA1c was weakly observed in a New Zealand study of 250 overweight and obese adults aged more than 18 years. (McGill AT et al 2008) Whereas another study of 7,198 British Caucasians showed a nonlinear inverse relationship between vitamin D and HbA1C (Hyppo"nen E and Power C 2006). Alemzadeh et al. found a significant relationship between $25(\mathrm{OH})$ and HbA1c in Caucasians, but not in African Americans (Alemzadeh $\mathrm{R}$ et al 2008). From these studies, it is evident that the association between vitamin $\mathrm{D}$ status and HbA1c is age dependent. These studies may also reflect a role for ethnicity in this relationship. In a study carried out by Guasch et $\mathrm{al}$, there was an association between $25(\mathrm{OH})$ D3 concentrations and hypertriglyceridemia component of the metabolic syndrome. ( Guasch. A et al 2012)

Vitamin D has been shown to have a role in insulin production, secretion and insulin resistance. In recent years, it has become apparent that for optimal functioning of many organs and tissues throughout the body adequate levels of Vitamin D is also important. Vitamin D receptors are identified in heart, smooth muscle, islets cells of pancreas which secrete insulin and immune cells. (Nagpal S and Rathnachalam R 2005, Bikle DD 2003) It has been also demonstrated that Islets cells of pancreas and immune cells possess 1 alpha hydroxylase enzyme required for synthesis of vitamin $\mathrm{D}$, vitamin $\mathrm{D}$ receptor and vitamin D dependent calcium binding proteins, suggesting an important role of vitamin D in insulin secretion. (Kajikawa M et al 1999, Bland $\mathrm{R}$ et al 2004) Vitamin D circulates in the bloodstream with its complex proteins particularly lipoproteins. Hormonal form of vitamin D i.e. calcitriol is able to increase the lipoprotein lipase activity in adipocytes resulting in removal of triglyceride enriched with lipoproteins from the blood. Previous studies also showed similar results in diabetic individuals when compared with the non-diabetic individuals. (Potolitsyna NN et al 2011)

Non diabetic individuals with deficient status of vitamin D levels might have greater risk of developing type 2 diabetes mellitus in near future, than individuals with normal vitamin D levels.

\section{Limitation of Study}

BMI adjustments for parameters are not done because medical records about height and weight are not available for all patients.

\section{Conclusion}

Deficient levels of vitamin D may predispose euglycemic person for diabetes and dyslipidemia. Vitamin D supplements in euglycemic individuals may play an important role in reducing the risk, which requires more studies.

\section{References}

1.Alemzadeh R et al (2008) "Hypovitaminosis $D$ in obese children and adolescents: relationship with adiposity, insulin sensitivity, ethnicity and season". Metabolism.57:183-191

2.Ashraf AP et al. (2011) "Association of serum 25 hydroxy vitamin D and components of the metabolic syndrome in obese adolescent females". Obesity. 19: 221421

3.Bikle DD. (2003) "Clinical counterpoint: Vitamin D: new actions, new analogs, new therapeutic potential," Endocr Rev, 13 : 76584. 
4.Bland R et al (2004) "Evidence for auto/paracrine actions of vitamin $\mathrm{D}$ in bone: 1 alpha hydroxylase expression and activity in human bone cells," J Steroid Biochem Mol Biol, 89-90 121-125

5.Bourlon PM, Billaudel B and Faure-Dussert A. (1999) "Influence of vitamin D3 deficiency and 1, 25 dihydroxyvitamin D3 on de novo insulin biosynthesis in the islets of the rat endocrine pancreas," J Endocrinol 160 (1) 8795

6.Cade C and Norman AW. (1986) "Vitamin D3 improves impaired glucose tolerance and insulin secretion in the vitamin D- deficient rat in vivo" Endocrinology 119(1) 84-90

7.De Luca HF. (2004) “Overview of general physiologic features and functions vitamin D," Am J ClinNutr, 80(6) 1689S-1696S

8.Guasch. A et al. (2012) "Plasma Vitamin D and Parathormone are Associated With Obesity and Atherogenic Dyslipidemia" Cardiovasc Diabetol.11: 149

9.Hyppo"nen E and Power C (2006) Vitamin D status and glucose homeostasis in the 1958 British birth cohort: the role of obesity. Diabetes Care; 29:2244-2246

10.Jessica A A and Ambika A (2010) "Role of Vitamin D in Insulin Secretion and Insulin Sensitivity for Glucose Homeostasis." Int J Endocrinol. .351-385.

11.Kajikawa M et al (1999) "An insulinotropic effect of vitamin $D$ analog with increasing intracellular $\mathrm{Ca} 2+$ concentration in pancreatic beta cells through nongenomic signal transduction," Endocrinology, 140(10) 4706-4712.

12.Ken C C et al.(2004) "Hypovitaminosis D is associated with insulin resistance and $\beta$ cell dysfunction." Am Clin Nutr , 79:.820-825

13.Kositsawat JMDM et al. (2010) "Association of A1C levels with vitamin D status in U.S. adults: data from the National Health and Nutrition Examination
Survey," Diabetes Care, 33 1236-1238

14.Nada AM. (2013) "Correlation between vitamin D3 and fasting plasma glucose, A1C and serum lipids in non-diabetic subjects" Z.U.M.J. 19(4)

15.Maestro B et al (2000) "Stimulation by 1, 25- dihydroxyvitamin D 3 of insulin receptor expression and insulin responsiveness for glucose transport in U-937 human promonocytic cells," Endocr J, 47(4) 383-91

16.Marie-H. G et al (2009) "Vitamin D in relation to metabolic risk factors, insulin sensitivity and adiponectin in a young Middle-Eastern population". European Journal of Endocrinology 160:.965-971

17.Maxwell CS and Wood RJ (2011) "Update on vitamin D and type 2 diabetes," Nutr Rev, 69(5) 291-5

18.McGill AT et al. (2008) "Relationships of low serum vitamin D3 with anthropometry and markers of the metabolic syndrome and diabetes in overweight and obesity." Nutr J $.7: 4$

19.Nagpal S and Rathnachalam R.(2005) "Noncalcemic actions of Vitamin D receptor ligands," Endocr Rev, 26 662-87

20.Ponda MP et al (2012) "Vitamin D may not improve lipid levels: A serial clinical laboratory data study", Circulation, 126(3) 270-7

21.Potolitsyna NN et al (2011) "Lipid metabolism indices and their correlation with vitamin $\mathrm{D}$ levels in indigenous populations of Northern European Russia," Human physiology.37 (2) 184-187

22.Rodriguez E et al.(2009) "Vitamin D in overweight/obese women and its relationship with diabetic and anthropometric variables" Obesity 17(4) 77882

23.Taheri E et al. (2012) "The relationship between serum 25-hydroxy vitamin D concentration and obesity in type 2 diabetic 
patients and healthy subjects," Journal of diabetes and metabolic disorders, 11 -16

24.Talaei A, Mohamadi M and Adgi Z. (2013) "The effect of vitamin D on insulin resistance in patients with type 2 diabetes," Diabetology and metabolic syndrome, 5 -8
25.Wang C (2013) "Role of vitamin D in cardiometabolic diseases," Journal of diabetes research , 1-10

26.Wang TJ et al (2008) "Vitamin D deficiency and risk of cardiovascular disease," Circulation, 117(4) 503-11

Vijetha Shenoy, Priyanka Datta, Krishnananda Prabhu and Kriti Singh (2014), Journal of Research in Diabetes, DOI: $10.5171 / 2013.929743$ 